with water and soap.' "It reconciles him to the dirt attendarit on the rubbinc-in."

"If constipation ensues, it must only be combated with medicines, when at the end of forty-eight hours it makes no semblance of disappearance. Then a clyster of poppy oil is the best remedy.

"The treatment, to be successful, must comprehend all these means. The author begs to enter his protest against a partial employment of the remedies recommended."

The only inconvenience, Dr. Schneemann has remarked, where the patient goes out on the tentl day, is "a little stiffness of the neck, which, however, passes off in twenty-four to thirty six hours, and requires no remedies of consequence."

Complications.-- 1 . Severe cerebral symptoms at the commencement of scarlet fever.

'The above method of treatment can naturally only be applied where time is allowed for the development of the restorative process, whereby the re-establishment of order in the system is produced. Occasionally the case is accompanied at its very outset by severe cerebral affection and convulsions. Here bleeding may be employed, and if necessary, unhesitatingly repeated.' To support this view, Dr. Schneemann instances the authority of Armstrong, Bernd, Stieglitz, Hammond, Ylingeston, \&c. Venesection is, accordingly, the sheet anchor. 'Other remedies are-1. The application of concentrated cold to the head, and the best form for this is ice. The cold dash is often more hurtful than useful, on account of the serious reaction which follows it, and exposes the patient more to the dangers of an apoplectic attack, although its results for the minute are often very flattering. At the end of every two hours, the bladder of ice should be removed, in order that the unintermpted effect of the cold may not weaken too much the tone of the vessels of the brain.'

Warm mustard plasters to the shins are a most valuable remedy.'

'Internal remedies are generally of very little use where the above-given remedies fail; the only one of any importance is the carbonate of ammonia. Mercury is of little value, except just to open the bowels; for its specification never comes into full play till the system is throwing off the affection. There are, however, much better purgatives than calomel; the saline, for instance. Emetics ought not to be tried in cases complicated with cerebral affection; in others they may. The aconite failed in the author's hands, both in tincture and solution.'

'With regard to the treatment by leeches and ammonia, so many writers have already pointed out its good results, that the author can safely recommend it, but with the proviso, that in urgent cases bleeding be substituted for leeches.'

§ 2. The Affection of the Throat. a. Primary.- As this is but a link in the whole, so must the measures taken for its removal be such as will remedy the general affection.'

'b. Secondary.-For this, the rubbing-in, as it acts by prophylaxis, is the best possible remedy; but where this has not been brought into use, or where, from keeping the patient too warm, desquamation has come on, and the secondary sorethroat has set in, the best remedy is emetics;" "they not only remove the tough glazy slime, but excite the secretions and excretions to more equality and normal disposition, and this is especially the case if the disorder have a more gastric character." (See Dewees, Pitschaft, Sundelin, Seifert, \&c.) Mariy, by confounding the employment of emetics in the early and latter stages, have brought them into discredit. For the swelling of the tonsils an excellent remedy is, a solution of nitrate of silver, (twenty grains to an ounce of water,) with which they and the soft palate are to be painted; but so many varieties present themselves in these secondary attacks follow ing on scarlet fever, that no gencral rules can be laid down. Here everything depends on the discrimination and judgment of the practitioner." "Another proof how necessary it is at once to quell the disorder on the principles above laid down."

Dr. Schneemann's opinion is, that scarlet fever is infectious, but that it is not so certain as to whether it is or is nct miasmatically or otherwise engendered, and sporadic in certain cases. 'Thuessink met with a case where a young man, from bathing in cold weather, was attacked by scarlet fever, which spread through the whole family! Hence it may perhaps be assumed that the disease may appear as epidemic and infectious, or only infectious, but not epidemic without being infectious; but then there must be present that peculiar disposition of the body which will receive the scarlet fever, or else it will not develop itself, and according to the reciprocal intensity of this disposition and of the infection, will the nature of the case be. Above all things, colds seem to predispose to an attack more than anything else, and girls seem more inclined to it than boys. Warm clothing, separation from school, and above all, light diet, so that the stomach be not overloaded, are the best preventives. That the younger children, as more predisposed than the others, must be more carefully separated from the sphere of infection, is doubtful practice. Not only are many children never infected, who, however, by adopting this system, require to be as carefully secluded as the others, thus causing great inconvenience; but the mildening influence and actual advartage of a gradual accustoming to the infection are thereby lost, and consequently the attack, when it comes, is so much the more severe: hence he rather counsels the free communication with the paticnt, in order that constant exposure may, as in the case of physicians and nurses, blunt and wear out the disposition to the disease; for as it now is, children are separated from the patient during the first period, which is the mildest, and exposed to contact with him during the process of desquamation, which is the source of the miost dangerous infection.' 'Many preservatives have been vaunted against this malady during its epidemic appearance; of these, however, the only one apparently deserving of much credit is the belladonna, which was recommended by Hahnemann. Its action appears to be, "by altering the relations of the nervous system, to diminish the disposition to the disease." Thus, when it is moderate, the belladonna extinguishes it; and when high, diminishes it. Of this the author has in many instances practically convinced himself. In numerous instances, only one child of a family was attacked. His prescription is-Take of extract of belladonna, one to two grains; distilled water, one ounce. Mix. To each child are to be given, morning and evening, as many drops as it has years. It is to be continued at least fourteen days.'

But not to confine himself to his own testimony, Dr. Schneemann gives that of Jördens, Ettmüiler, Hedenns, Gumpert, Hufeland, Martius, Pormey, Behr, Benedix, Thaer, \&c., (for which see Pamphlet, ch. v.,) who have testified to the value of belladonna; and though, he says, as many opponents might be found, yet it is scarcely credible that all the former had deceived themselves. In certain sections of the circle of Bayeux, Dr. Feron preserved from scarlet fever all the children who had not been attacked before he commenced operations. In 400 cases near Valenciennes, treated with belladonna, not one person was attacked. Hahnemann has, however, only recommended it where the eruption is smooth, bright-red, and in large patches. But where there are roughness and purpleness of the skin, it seems to be useless; and it may be that the bad success of many cases was owing to the neglect of this distinction.

Concluding Remarks.-After remarking on the great benefits which must follow a system capable of checking a disease so universal, the author requests all who may avail themselves of it to communicate the results to him or to the world. The theory he has drawn is of little consequence, but the facts are invaluable. Spilsbury recommended this system of treatment in the wasting fever and night-sweats of the consumptive; and Dr. Schneemann hints that it might be of use in measles and cholera.

\section{ON THE \\ TREATMENT OF CHOLERA, AS SUGGESTED BY SYDENHAM.}

By MARRis WiLSON, M.D. \&c., London.

An excellent proposition was suggested by a correspondent signing himself "Pater," published in The LANont of July 28 th last, and advocated by you in a leading article of the following week, for the meeting of a medical congress to inquire into the mode of treating the present epidemic scourge cholera.

I am sorry to say, the result has not been productive of the good which might have been anticipated. Instead of having one course of treatment established on clear, pathological principles, and on which, from its self-eridence, we could rely, medical men have come forward with such separate and unconnected methods of cure for the disease, that more than half the benefit has been lost for want of a proper classification of the remedies.

Happily for their patients, it appcars that in the hands of the various proposers, their mode of treatment has been tolerably successful; but the effect on the mind of the public, on the contrary, is one of considerable alarm at the confusion and want of agreement entertained by medical men among themselves on the subject.

There has also been another serious result of this unphilosophical proceeding, that, following the example of the 
profession, pretenders to the knowledge of medicine are putting forth their nostrums, addressed to the too credulous, in the columns of newspapers, to the great danger and detriment of the public. The object desired, is to have the principle of treatment for this malady carefully laid down, leaving it to the judgment of the practitioner to select the medicament which will most surely accomplish the end in view.

A great and useful object would be gained in setting at rest the public anxiety, by its being known that the principles of the treatment of the disease were thoroughly understood, and that the sole object of trying the various remedies proposed, is to arrive, in the readiest and most certain manner, at the accomplishment of those few principles. Thus the empirical system of giving, at random, so called specifics for the cure of the disease, would resolve itself into one of a treatment based upon its pathology.

There is a little to say with respect to the history of cholera. It would appear that there is an idea very generally adopted, that the disease known as Asiatic cholera is of recent origin-in fact, that it was unknown in England, at least, before its last violent access in the year 1832. But why such an idea should have been entertained in the face of very precise and marked descriptions of the malady to the contrary, I cannot imagine. Let us see what was known on the subject in the year 1669 .

That "worthy and excellent practical physician, Dr. Thomas Sydenham," when speaking of the "epidemiclk constitution" of part of the year 1669 , and three following, at London, says: At the beginning of August, 1669 , the cholera morbus, the gripes without stools, and the bloody flux, were very frequent whereas for ten years before they seldom happened." Further on, he gives a description of the symptoms of cholera morbus and in that distinctly points out, that the disease now considered a stranger, and of modern Asiatic origin, was well known, and distinguished from the commoner malady of surfeit or diarrhcea, long before the time of his then writing. He says: "That disease comes as certainly at the latter end of summer and at the approach of autumn as swallows at the beginning of spring, and as cuckoos at the heat of the following season. That disease, which is occasioned by a surfeit, comes at any time; the symptoms are, indeed, alike, and the cure the same, yet 'tis of another kind. The disease is easily known; for there are violent vomitings, and an evacuation of ill humours, with great difficulty and trouble by stool; there is a violent pain and inflammation of the belly and guts; an heartburning thirst, a quick pulse, with heat and anxiety, and often a small and unequal pulse, with great nauseousness, and sometimes a colliquative sweat; contractions of the arms and legs, fainting, a coldness of the extreme parts, and suchlike symptoms, which frighten the bystanders, and kill the patient in twenty-four hours."

In the method of treatment proposed by him, he considers it improper either to evacuate or astringe the bowels in too great a degree-choosing, as he says, a middle way. He proposes to clear out the "sharp and acrimonious humours," by taking chicken broth to vomiting, and, at the same time, removing offending matter from the bowels by using broth for clysters. He then administers an anodyne-his own quaint formula being:- Take of cowslip water, one ounce; of aqua mirabilis, two drachms; of liquid laudanum, sixteen drops. Mix them. Though he adds, "any other narcotick of the shops may be used instead of it." And "if the vomiting and looseness have continued many hours, suppose ten or twelve, and the sick is worn out, so that the extreme parts wax cold, I say in this case, all other remedies being omitted, the physician must immediately fly to laudanum, the sacred anchor in this disease, which must not only be given when the symptom are urgent, but also after the vomiting and looseness go off."

The succeeding remarks are so pertinent to the entire question of cholera, the season of the year, and probable duration of the true disease, and express so shrewdly some of the speculations of the present day, that I feel called on to quote them also. The Doctor says:-

Though this disease is epidemical, as was said before, yet it very seldom lasts longer than August, wherein it first began; upon which account I have been induced to consider the excellent contrivance of nature for the production of epidemick diseases; for though the same causes wholly remain, so that many should be seized with this disease as well in September as August, by reason of eating too much fruit, yet we see the same effect does not follow; and he that shall carefully observe the phenomena of a legitimate cholera, will confess that that disease which invades at any other time of the year, though coming upon the same occasion, and accompanied with some of the same symptoms; is altogether different from this now spoken of, as if there were some secret and peculiar thing in the air of this peculiar month that impresses on the blood or on the fermont of the stomach some such specifick alieration as is fit only for the disease."

In the year 1676 the cholera again visited London, and apparently with as much, or even greater violence than before, and attended with more violent spasms. In this he recom mended the same method of treatment, but with a larger dose of laudanum. In a case attended by him and Dr. Groodall, when called to a patient just dying, by reason of the violence of the convulsions, in a cold sweat, with his pulse scarcely to be felt, and with violent vomiting, twenty-five drops of liquid landanum were given for a dose, in a spoonful of cinnamon water, and the dose repeated in half an hour, and as the symptoms were apt to recur on the least motion, smaller doses were repeated at intervals: the case terminated favourably.

From all this it will be seen that the epidemic now raging is by no means new in the annals of medicine, nor does its treatment seem to have been in such uncertainty two hundred years ago as at the present time.

I am not now entering into the relative merits of the leading methods of treating the malady, but I feel satisfied that the landanum treatment which proved successful in the hands of so practical a physician should not carelessly be set at naught.

I am somewhat supported in this view, since nearly every mode of treatment proposed admits more or less the use of some preparation of opium, and though perhaps in the collapsed state its sedative effect is not the one to be desired; 1 consider that its stimulant qualities have a peculiar power in sustaining the vital energies until other remedies have suff: cient time to act.

I do not quite agree with Dr. Syderham in his idea that true cholera terminates in the month in which it has made its com mencement, neither that it is confined to August, since I have often seen fatal cases at other seasons of the year. Nor am I satisfied that opium alone can be found sufficient for the treatment of the disease; but in considering it, the sedative power is not to be regarded as the only one it possesses.

Upper Charlotte-street, Fitzroy-square,-Sept. 1849.

REPORT OF A

\section{CASE OF SNAKE-BITE, AND RECOVERY.}

\section{BY FRED. J. BEARDMORE, Esq., M.R.C.S.E., Sydney,} New South Wales.

ON the 7 th of Dee. 1848, a young woman, aged about twenty, was walking in a garden on Milsom's Point, and suddenly felt as if stung with needles in the back and lower part of the calf; but not seeing a snake, she was uncertain what to do, until swelling of the leg and uneasy feelings cansed her to send for medical aid, which arrived about eleven o'clock A.M., nearly two hours after the accident. On examining the part; a blue mark, like an old bruise, three inches long, curved downwards, and shaped like the forefinger, appeared; at the upper part of this mark might be seen, with close inspection, four to six very minute red spots. These spots (through which, doubtless, the venom had been conveyed) were cut out, with the adjacent skin, according to Dr. Bland's method-a ligature was applied directly above the part, and the foot was immersed in hot water. Very free bleeding ensued: As the patient was getting very drowsy, ammonia, camphor, brandy, and small doses of laudanum, were administered; the patient was kept roused, and a breast-pump applied to the wound, and caustic. Drowsiness increasing, at the request of some persons present an ipecacuanha poultice was applied. On the patient getting worse, mustard ponltices were applied-successively down the back, and seemed to have considerable effect in keeping the patient awake; but in spite of stimulants and constant arousing, the drowsiness and the intervals of unconsciousness increased. The appearance of the patient was at this time (four hours after the accident) deplorable: a constant winking of the eyes, insensibility for three minutes together, waking for a moment to ask "Shall I get over it?" then sinking lack apparently insensible; yet, when again aronsed for a moment she related with accuracy every circumstance connected with the accident, and said that she felt no pain. Her Christian name, as is usual, was most successful in calling forth an answer. Towards two o'clock, Dr. O'Brien, of Castlereaghstreet, arrived from Sydney; the stimulants, counter-irritation, \&c., were continued. About this time, a flush appearing to pass over the face, eight or ten leeches were applied to the temple. At this time I left, but understood that, not long afterwards, the drowsiness began to abate, and at six o'cloek 